Estudos RBEP

\title{
As proposições de uma escola inclusiva na concepção de professores de educação especial: algumas problematizações
}

\author{
Mariana Luzia Corrêa Thesing ${ }^{\mathrm{I}}$ II \\ Fabiane Adela Tonetto Costas ${ }^{\mathrm{III}, \mathrm{IV}}$
}

http://dx.doi.org/10.24109/2176-6681.rbep.99i252.3510

\footnotetext{
Universidade Federal de Santa Catarina, Florianópolis (UFSC), Santa Catarina, Florianópolis, Brasil. E-mail: < marluzcor@ gmail.com>; <https://orcid. org/0000-0001-5864-7091>.

II Doutoranda em Educação na Universidade Federal de Santa Maria (UFSM). Santa Maria, Rio Grande do Sul, Brasil.

III Universidade Federal de Santa Maria (UFSM). Santa Maria, Rio Grande do Sul, Brasil. E-mail: <fabicostas@ gmail.com>; <https://orcid. org/0000-0003-3698-2782>.

Iv Doutora em Educação pela Universidade Federal do Rio Grande do Sul (UFRGS). Porto Alegre, Rio Grande do Sul, Brasil.
}

\section{Resumo}

Que ações são necessárias para a efetivação de uma escola, de fato, inclusiva, nos moldes propostos pela Política Nacional de Educação Especial na Perspectiva da Educação Inclusiva (Brasil. MEC, 2008)? Com base nesse questionamento, este artigo apresenta resultados de uma pesquisa realizada com professores de educação especial atuantes em quatro municípios do Rio Grande do Sul que indicam ações necessárias para a criação de uma nova escola: uma escola inclusiva. A pesquisa, baseada em uma abordagem qualiquantitativa (Marconi; Lakatos, 2009), com a utilização de um questionário disponível no Formulários Google, teve como objetivo conhecer as trajetórias formativas e as características dos contextos de atuação docente desses professores. Com base em referências como Garcia (2013, 2014), Kassar (2014), Michels (2011) e Correia (2010), este texto apresenta parte dos dados coletados e problematiza as proposições dos professores de educação especial para a possibilidade de transformar as escolas em espaços efetivamente inclusivos. Como resultado deste 
estudo, percebe-se que a maioria dos professores participantes acreditam nos processos de inclusão nas escolas em que estão inseridos; contudo, sinalizam a importância de ações, de diferentes sujeitos envolvidos na educação escolar, para que a proposição de uma escola inclusiva se torne uma realidade.

Palavras-chave: ações pedagógicas; inclusão; professor de educação especial.

\section{Abstract \\ Proposals for an inclusive school in the special education teachers' view: some problematizations}

What are the necessary actions to implement a truly inclusive school, as proposed in the National Policy for Special Education in the Perspective of Inclusive Education (Política Nacional de Educação Especial na Perspectiva da Educação Inclusiva - Brasil. MEC 2008)? Through this inquiry, this article presents the findings of a research involving special education teachers of four municipalities of Rio Grande do Sul who point out actions needed to create a new school: an inclusive school. This research, that follows a quanti-qualitative approach (Marconi; Lakatos, 2009), through the use of a Google Forms questionnaire, aims to uncover the formative paths and characteristics of these teachers' instructing environments. Based on the likes of Garcia (2013, 2014), Kassar (2014), Michels (2011), and Correia (2010), this paper presents some of the data collected in the research and problematizes the proposals of special education teachers to turn schools into effectively inclusive spaces. As a result of this study, it was observed that most of the participants believe in the processes of inclusion implemented by the schools in which they are placed; however, they flag the importance of implementing initiatives, from different actors in the school education, so that an inclusive school proposal can be effectively realized.

Keywords: pedagogical actions; inclusion; special education teacher.

\section{Introdução}

A Política Nacional de Educação Especial na Perspectiva da Educação Inclusiva (Brasil. MEC, 2008), ao defender a inclusão de sujeitos com deficiência, transtornos globais do desenvolvimento e altas habilidades/ superdotação em espaços regulares de educação escolar, exige uma nova escola e novos professores para a sua implementação. Antecedida 
por acordos internacionais ${ }^{1}$ e embasada em discursos que defendem os direitos universais, desafia a escola à inclusão de todos e responsabiliza seus professores na efetivação da pretendida reforma.

Nos últimos anos, as políticas voltadas à educação escolar inclusiva definiram caminhos e orientações na proposição de uma escola inclusiva e a defendiam, em nome de ideais progressistas, como uma possibilidade de tornar a sociedade mais inclusiva e solidária (Garcia, 2013). Num movimento não linear, estabeleceram o conceito de educação especial (Brasil. CNE. CEB, 2001, 2009; Brasil. MEC, 2008), instituíram o atendimento educacional especializado - AEE (Brasil, 2008; Brasil. CNE. CEB, 2009), determinaram o público-alvo a ser atendido nas escolas inclusivas (Brasil. MEC, 2008; Brasil, 2008; Brasil. CNE. CEB, 2009) e defenderam a formação de professores especializados e capacitados para a reforma (Brasil. CNE. CEB, 2001). Entretanto, apesar das políticas e das diretrizes voltadas à educação escolar inclusiva, as pesquisas realizadas sobre os processos de inclusão escolar denotam dificuldades para a sua efetivação (Schmidt et al., 2016; Anjos; Andrade; Pereira, 2009; Mendes; Almeida; Toyoda, 2011).

Diante desse cenário, este texto resulta de uma pesquisa realizada com professores de educação especial atuantes em quatro cidades do Rio Grande do Sul (Bagé, Santa Maria, Santana do Livramento e Uruguaiana). A investigação, de abordagem qualiquantitativa (Marconi; Lakatos, 2009), teve como objetivo conhecer os diferentes aspectos da trajetória formativa desses professores e de seus contextos de trabalho profissional. Baseada em um questionário, com questões sobre as trajetórias profissionais e os contextos de trabalho dos professores, a pesquisa teve também como objetivo conhecer as crenças docentes sobre os processos inclusivos, as possibilidades e as dificuldades percebidas nesses contextos e as possíveis ações propostas por esses professores para a efetivação da escola inclusiva. Desse modo, tendo em vista os resultados observados, este texto tem como objetivo central apresentar e problematizar as ações propostas pelos professores participantes para transformar os contextos escolares em que trabalham, com base na crença de que uma escola efetivamente inclusiva seja possível.

\section{Trajetória investigativa}

A pesquisa, de abordagem qualiquantitativa (Marconi; Lakatos, 2009), foi realizada por meio da aplicação de um questionário no formato Formulários Google, enviado aos endereços eletrônicos de professores de educação especial de quatro cidades do Rio Grande do Sul (Bagé, Santana do Livramento, Uruguaiana e Santa Maria). A coleta dos dados ocorreu exclusivamente via questionário, em diferentes momentos. No primeiro semestre de 2016, os questionários foram enviados aos professores de educação especial de Bagé, Santana do Livramento e Uruguaiana. A escolha
Declaração Mundial sobre Educação para Todos (1990), Declaração de Salamanca (1994). 
por esses sujeitos se deveu à formação desses professores: a maioria é egressa da versão inicial do Curso de Graduação de Educação Especial a distância da Universidade Federal de Santa Maria (UFSM/RS), proposto como primeiro curso de graduação na modalidade a distância dessa instituição, no ano de 2005. Nessa fase, foram enviados 74 questionários e recebidas 24 respostas. Esses professores atuantes nos municípios Bagé, Santana do Livramento e Uruguaiana exercem suas atividades na esfera estadual de ensino, e as coordenadorias ${ }^{2}$ autorizaram e disponibilizaram seus endereços eletrônicos.

A fim de conhecer a realidade dos professores de educação especial de Santa Maria (RS) - cidade em que três cursos de formação de professores de educação especial (dois presenciais ${ }^{3}$ e um a distância) são ofertados em uma instituição de ensino superior pública -, o questionário foi enviado a 49 professores de educação especial atuantes na esfera municipal de ensino. Os endereços dos docentes foram fornecidos pela Secretaria Municipal de Educação, a qual autorizou o desenvolvimento da pesquisa.

O questionário, enviado em mais de uma situação aos participantes, continha $32^{4}$ questões cujas respostas poderiam ser registradas de diferentes formas: múltipla escolha, escolha única e textuais. O caráter das respostas foi estruturado da seguinte maneira: 15 questões ofertavam a possibilidade de múltipla escolha; 9 a possibilidade de resposta única e 8 a possibilidade de escrita. As questões abordavam temáticas referentes à formação inicial, ao tempo de serviço, aos sujeitos da educação especial atendidos, às características organizativas dos contextos de trabalho e às possibilidades e dificuldades percebidas nesses espaços.

Perguntamos aos professores sobre as crenças no processo de inclusão na escola regular, as dificuldades e possibilidades percebidas e as proposições que consideravam necessárias para transformar as escolas regulares em espaços inclusivos. Desse modo, com o objetivo de conhecer as ações, foi proposto o seguinte questionamento: "Qual(is) ação(ões) você considera pertinente(s) para a efetivação dos processos inclusivos na realidade escolar em que você atua?". Mediante essa questão, em que os professores tinham a possibilidade de descrever suas respostas, algumas alternativas e ações foram apresentadas, as quais contemporizam com as proposições da Política Nacional (Brasil. MEC, 2008).

\section{Resultados e discussões}

A pesquisa realizada com os professores de educação especial justifica-se pelo interesse em dar voz a esses docentes que são considerados ora "objeto", ora "instrumento" (Evangelista; Triches, 2014) para a reforma proposta (Brasil. MEC, 2008). Os resultados deste estudo, por meio da análise de conteúdo (Bardin, 1977), sinalizam que os professores participantes, em sua maioria (27/33), acreditam nos processos de inclusão dos sujeitos

\footnotetext{
2 As Coordenadorias Regionais de Ensino (CREs) referem-se à $13^{\mathrm{a}} \mathrm{CRE}$ (Bagé); à $19^{\mathrm{a}} \mathrm{CRE}$ (Santana do Livramento) e à $10^{a}$ CRE (Uruguaiana).

3 A Universidade Federal de Santa Maria oferta três diferentes cursos de formação inicial em educação especial e dois na modalidade presencial: um no período diurno e outro no período noturno. O primeiro curso, criado em 1984 como uma licenciatura, oferece 50 vagas. O curso noturno, criado em 2009, a partir do Programa de Apoio a Planos de Reestruturação e Expansão das Universidades Federais Brasileiras (Reuni), oferece 45 vagas.

4 Dessas questões, 31 eram consideradas obrigatórias, não permitindo que o participante pudesse desconsiderá-las.
} 
O público-alvo da educação especial diz respeito a estudantes com deficiência, transtornos globais de desenvolvimento e altas habilidades/ superdotação (Brasil, 2008; Brasil. CNE.

6 Os avanços citados pelos professores referem-se, de forma majoritária, à aprendizagem dos estudantes público-alvo da educação especial (29/33), ao trabalho articulado com os professores das salas de aula comum dos estudantes atendidos (25/33), ao apoio da equipe pedagógica das escolas (20/33), à frequência assídua dos estudantes com deficiência (20/33), ao apoio das famílias dos estudantes (17/33).

7 As dificuldades citadas pelos professores referem-se à falta de apoio das famílias dos estudantes incluídos (22/33), à falta de uma equipe multidisciplinar de profissionais nos municípios que atendam aos estudantes (21/33), à suposta falta de conhecimentos específicos dos professores das salas de aula comum sobre a inclusão (21/33), à falta de suporte da equipe pedagógica das escolas (11/33) e à baixa frequência dos estudantes aos atendimentos (11/33) público-alvo da educação especial ${ }^{5}$ nas escolas regulares. As respostas dos professores foram analisadas considerando os três momentos da análise de conteúdo propostos por Bardin (1977). Inicialmente, foi realizada uma leitura flutuante das respostas na busca por elementos relevantes para a pesquisa; em um segundo momento, esses elementos foram organizados de forma mais detalhada e sistemática; e, num terceiro momento, foram identificadas e analisadas as aproximações e os distanciamentos entre as respostas.

De forma geral, as respostas dos docentes sinalizam a defesa da inclusão escolar como um direito subjetivo; como uma possibilidade de tornar a sociedade mais inclusiva; e como a superação de uma escola excludente e segregacionista. Os professores, quando questionados sobre a importância da inclusão de sujeitos com deficiência na escola regular, afirmam a relevância da proposição de uma escola inclusiva porque:

[...] qualquer pessoa é capaz de aprender. É muito importante para um aluno com deficiência frequentar a escola junto aos seus pares, com todas as diferenças que existem. (Professora A, 2016).

Todos crescem com as trocas de experiências e cada aluno é especial com ou sem deficiência, cada um tem seu ritmo de aprendizagem e as conquistas são compartilhadas e as dificuldades quase sempre são superadas com o esforço de todos. (Professora B, 2016, grifos nossos).

[...] mesmo sem toda a estrutura necessária, já consigo visualizar muitos benefícios da inclusão escolar. Para os alunos incluídos, a constante estimulação e evolução em todos os sentidos, e para toda a comunidade escolar, o desenvolvimento de um sentimento de respeito às diferenças e compreensão de que, sim, é possível aprender de maneiras diversas e em tempos diversos. (Professora C, 2016, grifos nossos).

Apesar dos avanços ${ }^{6}$ que percebem em seus contextos de trabalho, os professores de educação especial apontam muitas dificuldades ${ }^{7}$ a serem ainda superadas, comuns às realidades em que atuam. Diante dessas dificuldades que, segundo eles, vão desde a falta de apoio das famílias dos estudantes até a falta de comprometimento de alguns professores, propõem ações que consideram necessárias para a concretização da inclusão nas escolas regulares. Mesmo com as diferenças contextuais desses cenários escolares, as proposições dos professores corroboram, em sua maioria, os discursos que defendem a formação de um novo professor, aprendente e flexível, e uma nova escola, mais acolhedora e inclusiva.

Com base nessas proposições, percebem-se dois eixos de ações designadas a diferentes sujeitos: as relacionadas às equipes diretivas, às esferas governamentais e às famílias dos estudantes com deficiência; e aquelas designadas aos professores das salas de aula comum que atuam com os sujeitos público-alvo da educação especial. Desse modo, este texto tem a intencionalidade de apresentar e problematizar as proposições dos professores de educação especial, voltadas às ações escolares, governamentais e comunitárias e àquelas atribuídas aos docentes. 


\title{
Ações escolares, governamentais e comunitárias: proposições para uma escola inclusiva
}

Esse conjunto de ações se refere a proposições docentes que envolvem a ação de outros sujeitos relacionados aos contextos escolares: as equipes pedagógicas/diretivas das escolas, as esferas governamentais e as famílias dos estudantes. As ações mencionadas, de forma geral, estão relacionadas a uma estrutura de apoio que é necessária para o desenvolvimento do trabalho pedagógico na escola com os estudantes incluídos. Entre as proposições, algumas sinalizam a necessidade de organização de espaços e tempos de planejamento pedagógico entre os diferentes professores na escola, a promoção de eventos e cursos de formação continuada e o maior apoio nos processos de mediação entre a escola e as famílias dos estudantes com deficiência.

A falta de organização de espaços e tempos para o trabalho articulado entre os professores é um elemento bastante citado pelos participantes. As falas dos docentes indicam a importância do trabalho articulado entre professores de educação especial e os da sala de aula comum como uma ferramenta de apoio nos processos de ensinar e aprender na escola inclusiva (Costas; Honnef, 2015). Os docentes assinalam a necessidade de "reuniões periódicas entre professores de atendimento educacional especializado (AEE) e da sala regular", de "tempo para um trabalho em conjunto", de "maior interação entre professores do AEE com professores das turmas", de "horário para planejar e estudar, espaço físico e materiais para planejamento", de "planejamento coletivo", de "mais momentos de formação nas escolas" e de situações em que seja possível a "atuação do professor de AEE com o professor da sala de aula comum". Para Costas e Honnef (2015, p. 3), o trabalho docente articulado é uma ferramenta essencial para práticas efetivamente inclusivas, visto "que um trabalho conjunto entre os professores de educação especial e de classe comum pode ser benéfico a ambos, pois as aflições e incertezas podem ser divididas". As autoras também mostram que, diante do trabalho articulado, a responsabilidade de construir estratégias de ação é compartilhada por todos os professores, o que contribui para a efetivação de um trabalho com os sujeitos com deficiência "mais eficiente e satisfatório".

Nessa discussão, Vilaronga e Mendes (2014, p. 140) reiteram a importância do trabalho articulado ao afirmarem que pesquisas sobre práticas inclusivas

\begin{abstract}
têm demonstrado que os profissionais da escola que atuam individualmente nas salas de aula não possuem respostas para a maior parte das dificuldades apresentadas pelos estudantes e não são capazes de realizar processos reais de ensino para alunos com deficiência quando trabalham individualmente.
\end{abstract}

A formação de professores em serviço é também uma ação defendida pelos participantes da pesquisa. Segundo eles, é preciso que atividades de formação que discutam a inclusão escolar e possíveis estratégias 
para torná-la viável na escola sejam pensadas e propostas pelas equipes pedagógicas e pelas esferas governamentais. Nesse sentido, acreditam que cursos e eventos de formação sejam ações de apoio necessárias nos processos inclusivos, pois, entre as dificuldades percebidas por eles, está a suposta falta de conhecimentos específicos dos professores da sala de aula comum para o trabalho com a inclusão na escola (21/33).

Penso que o mais importante é romper com a "ignorância", pois só podemos nos apropriar daquilo que conhecemos, e a formação continuada é um meio possível para desmistificar as deficiências e mostrar o quanto a inclusão pode contribuir para o desenvolvimento humano. (Professora D, 2016).

É preciso que haja mais reuniões periódicas entre professores da AEE e sala regular, oferta de palestras aos professores da sala regular sobre as NEE [necessidades educativas especiais] para discutir formas de trabalho eficientes para a inclusão. (Professora E, 2016).

[...] é necessária a oferta de palestras aos professores da sala regular sobre as NEE e formas de trabalho eficientes para a inclusão dos alunos, e a formação continuada é um meio possível para desmistificar as deficiências. (Professora F, 2016).

O professor deve ser seguro do seu trabalho na escola para poder articular os conhecimentos teóricos com sua prática. Precisam ter formação e conhecimento. (Professora G, 2016).

A formação continuada de professores é considerada uma estratégia relacionada à garantia da qualidade e do direito de todos à educação, defendida na Conferência de Educação para Todos, na Tailândia, em 1990. Esse evento, sistematizado por organismos multilaterais como a Organização das Nações Unidas para a Educação, a Ciência e a Cultura (Unesco), o Fundo das Nações Unidas para a Infância (Unicef), o Programa das Nações Unidas para o Desenvolvimento (Pnud) e o Banco Mundial, foi um dos momentos mais importantes para os países emergentes, pois, a partir dele, foi definida a Declaração Mundial de Educação para Todos (Unesco, 1998), que se constituiu como um documento base para o planejamento de ações e políticas educacionais em diversos países, inclusive o Brasil. Nessa perspectiva, Bello e Bueno (2012, p. 7) afirmam que:

Tendo como base a Declaração Mundial sobre Educação para Todos, o Brasil elaborou em 1993 o Plano Decenal de Educação para Todos 1993-2003, com linhas de ação estratégica para responder às metas preconizadas em Jomtien. No que se refere ao magistério, esse documento indica que "embora o nível de titulação dos professores tenha aumentado nos últimos anos, persistem problemas de desempenho". Para mudar o quadro, é proposta a reestruturação dos processos de formação inicial e continuada, com ênfase para a última. Estabelece-se, mediante o discurso apresentado, uma relação direta entre o papel do professor e o desempenho dos sistemas de ensino.

A formação continuada de professores é também defendida na última Lei de Diretrizes e Bases da Educação Nacional (Lei nº 9.394/1996 e suas alterações) e também no Plano Nacional de Educação (PNE) vigente (Lei $\mathrm{n}^{\circ}$ 13.005/2014), que prevê a necessidade de contínua formação dos 
professores para a qualidade dos processos escolares (Metas 15 e 16). Esse documento também faz referência à importância da formação continuada como estratégia para a consolidação das propostas da Política Nacional (Brasil. MEC, 2008), ao declarar que se "deve assegurar a implantação, ao longo deste PNE, de salas de recursos multifuncionais e fomentar a formação continuada de professores para o atendimento educacional especializado nas escolas urbanas, do campo, indígenas e de comunidades quilombolas" (Brasil, 2014).

A formação de professores, nesse sentido, é veiculada como a solução para melhoria da qualidade do trabalho pedagógico nas escolas, assim como a premissa de que a educação inclusiva escolar é a solução para os problemas econômicos de uma sociedade excludente. Desse modo, numa relação de fatores associados, tornar a escola um espaço efetivamente inclusivo seria o primeiro passo para a constituição de uma sociedade mais inclusiva, e, para tal objetivo, é preciso haver professores bem formados que atendam às demandas dessa nova escola. Nessa discussão, Shiroma e Evangelista (2014) salientam que:

\begin{abstract}
A inversão ideológica se torna evidente na equação redutora: professor mal formado + escola de má qualidade + aluno mal preparado = pobreza nacional! A solução apresentada é simples: preparar adequadamente o professor + reestruturar a escola + qualificar mão de obra = desenvolvimento nacional! (Shiroma; Evangelista, 2014, p. 13).
\end{abstract}

Como um dos legados das pedagogias progressistas, é legítima a premissa de que todos podem e devem aprender durante a vida toda. Contudo, esse discurso salienta a incompletude de um professor que precisa aprender estratégias para atender múltiplas demandas no seu cotidiano de trabalho e que está, por isso, sempre em dívida nesse processo diante de um sistema educacional que "se quer inclusivo". O professor, em contínuo processo formativo, para dar conta de diferentes demandas em seus contextos de trabalho, é responsabilizado pelo insucesso de suas práticas: nessas situações, pode ser acusado de ter pouco conhecimento e/ou ineficiente formação para lidar com o inesperado. Sobre a defesa do slogan da "educação ao longo da vida", Rodrigues (2014) alerta para a super-responsabilização dos docentes diante das demandas na escola, culpabilizados por possíveis fracassos em contextos profissionais com condições precárias de trabalho.

Defendemos que a noção de educação ao longo da vida vai além das mudanças prescritas aos sistemas educacionais em seu conjunto; visa, acima de tudo, conformar uma relação de sujeitos na história, almejando no horizonte deste projeto educacional um sujeito despolitizado, atomizado, sem qualquer capacidade organizativa e sem condições de pensar-se como sujeito coletivo, apenas "homens-massa", na célebre expressão gramsciana. [...] Nesse "novo modelo", o sujeito deverá adaptar-se continuamente, corrigir seu percurso perante as necessidades do mercado e conviver eternamente com a culpabilidade das escolhas malsucedidas. (Rodrigues, 2014, p. 236). 
8 São considerados professores capacitados para atuar em classes comuns com alunos que apresentam necessidades educacionais especiais aqueles que comprovem que, em sua formação de nível médio ou superior, foram incluídos conteúdos sobre educação especial. (Brasil. CNE. CEB, 2001).

9 São considerados professores especializados em educação especial aqueles que comprovarem: I - formação em cursos de licenciatura em educação especial ou em uma de suas áreas, preferencialmente de modo concomitante e associado à licenciatura para a educação infantil ou para os anos iniciais do ensino fundamental II - complementação de estudos ou pós-graduação em áreas específicas da educação especial, posterior à licenciatura nas diferentes áreas de conhecimento, para atuação nos anos finais do ensino fundamental e no ensino médio. (Brasil. CNE. CEB, 2001).
Kassar (2014), ao realizar uma pesquisa sobre a formação continuada dos docentes para atuarem no AEE, destaca que grande parte dos professores, tanto os considerados capacitados ${ }^{8}$ quanto os especializados, ${ }^{9}$ são formados em instituições privadas ou nas modalidades a distância e/ou semipresencial em instituições públicas. A autora, ao discutir acerca dos processos de formação para professores, diante da proposição da educação inclusiva, revela:

Parece-nos que estamos diante de um grande desafio, considerandose que não há consenso - dentro da própria área - em relação à formação apropriada de professores para escolarizar satisfatoriamente a população historicamente identificada como "da educação especial". Esse consenso parece inexistir tanto para a formação do "capacitado" como para a do "especializado". (Kassar, 2014, p. 222).

Contudo, apesar dessa "falta de consenso" (Kassar, 2014), diante da defesa da formação continuada de professores para a educação inclusiva pelas políticas educacionais e pelos participantes da pesquisa, questiona-se: Quais são os saberes considerados necessários para esse novo professor trabalhar nessa nova escola? Que tipos de formação são ideais para a formação continuada/em serviço desses professores, tendo em vista suas jornadas de trabalho: palestras, reuniões pedagógicas, capacitações e/ou cursos de especialização? Tais tipos de cursos não estariam contribuindo para a desintelectualização dos professores, com propostas de capacitação que primam pela instrumentalização do professor para o uso de recursos metodológicos (Michels, 2011)?

Além do apoio das equipes pedagógicas/diretivas das escolas para a organização de espaços e tempos de planejamento compartilhado e de eventos de formação continuada, os docentes também indicaram a importância de as esferas governamentais demonstrarem maior apoio às práticas inclusivas, com a proposição de outras ações e políticas voltadas para a inclusão nas escolas, como a garantia de equipes multidisciplinares para o atendimento dos estudantes. Segundo eles:

A maior dificuldade encontrada no trabalho é a falta de uma equipe multidisciplinar e de profissionais de saúde para atuação direta com os estudantes com NEE. Aqui na minha cidade não existem profissionais especialistas que possam atender tais necessidades. O poder público e escola estão muito distantes neste processo. Acredito que, se não existisse esta distância, os alunos teriam muito mais chances de progresso neste processo. (Professora H, 2016).

Muitas ações seriam necessárias para a efetivação da inclusão. Primeiramente, não temos pessoal especializado necessário. A educação especial é normalmente a última a ser considerada. Temos escolas com 20, 30 alunos incluídos, sem nenhum professor especializado para o atendimento. Ou, então, um professor é convocado a ser itinerante, e tem que dar conta de três, quatro, cinco escolas, que deveriam ter um educador especial com carga horaria de $40 \mathrm{~h}$ semanais. Isso seria o mínimo. Há muitos outros fatores a serem considerados, mas não acredito que possamos sequer pensar na solução deles se ainda nem temos o básico que são os profissionais com qualidade e tempo necessários para um realizar uma real inclusão. (Professora I, 2016). 
Vejo que já conquistamos muito, porém, ainda temos um longo caminho a percorrer. Na escola em que trabalho (estado), temos dificuldade para encaminhar os alunos para atendimentos clínicos como fonoaudiólogo, psicólogo, neurologista. Os mesmos são encaminhados pela secretaria da saúde e o município não dá conta da demanda, o que muitas vezes prejudica nosso trabalho. (Professora J, 2016).

As equipes multidisciplinares são entendidas como essenciais para o trabalho pedagógico inclusivo na escola. A colaboração e a cooperação entre diferentes profissionais, com diferentes olhares e perspectivas de atuação, favorece a criação de estratégias para o atendimento dos estudantes com deficiência. Para Correia (2010), a constituição de equipes para apoiar a inclusão nas escolas é uma estratégia fundamental que envolve distintos sujeitos para pensar sobre a efetivação dos processos inclusivos. Segundo o autor, há pelo menos dois tipos de equipes consideradas necessárias: as de planejamento inclusivo e as de colaboração. As primeiras, compostas por professores e pais, seriam responsáveis pelo planejamento, pelo desenvolvimento e pela avaliação de um projeto inclusivo para as escolas, que mobilizasse toda a comunidade escolar. Já as segundas, chamadas também de "equipes de apoio ao aluno", estariam voltadas a pensar em estratégias de trabalho para os casos específicos de estudantes incluídos e envolveriam professores, pais e outros profissionais especializados, como psicólogos, fonoaudiólogos, terapeutas ocupacionais etc.

Para o autor:

Seja qual for a composição e organização, a equipe de apoio ao aluno deve, depois de analisada e recolhida informação sobre o aluno e seus ambientes de aprendizagem, discutir quais as melhores soluções para o aluno, ou seja, de posse da informação, a EAA deve proceder a uma planificação que permita efetuar uma intervenção educacional cujo fim seja o de minimizar ou até suprimir o problema do aluno. (Correia, 2010, p. 34).

Pensando em uma rede de apoio para o trabalho pedagógico inclusivo, alguns professores também relataram a necessidade de maior auxílio e participação das famílias dos estudantes para a escola ser, de fato, um espaço inclusivo. A "defesa da família como coautora nos processos inclusivos" está imbricada à necessidade percebida pelos professores de "estabelecer uma relação mais harmônica entre família e escola", a fim de que haja maior envolvimento das famílias nos processos escolares de seus filhos. Segundo os professores, é fundamental o "comprometimento de toda a comunidade escolar com o processo", a "frequência dos alunos no contraturno" e a consequente "mudança de mentalidade de toda comunidade escolar" para a constituição de espaços escolares inclusivos. Para eles, a participação da família nos processos de inclusão auxilia a aprendizagem e o desenvolvimento dos estudantes com deficiência.

A efetivação passa pela mudança de mentalidade de toda comunidade escolar e nas ações efetivas para que os alunos acessem o conhecimento e usem o direito que possuem à participação. (Professora K, 2016). 
Estabelecer uma relação mais harmônica entre família e escola para que os alunos se sintam parte da comunidade escolar. (Professora L, 2016).

Maior envolvimento da família e comprometimento de toda a comunidade escolar com o processo. (Professora M, 2016).

De acordo com essas falas, o envolvimento e a participação das famílias nos processos inclusivos são considerados imprescindíveis para a aprendizagem e o desenvolvimento dos estudantes com deficiência. Lopes e Marquezan (2010, p. 4) destacam

[...] que a participação da família do filho com necessidades especiais é decisiva no processo de integração/inclusão e indispensável para um construir-se pessoal e participante da sociedade. As relações entre famílias de filhos com necessidades especiais oportunizam suporte recíproco para o fortalecimento necessário à convivência saudável entre seus membros. A escola, em conjunto com a família, deverá implementar as melhores estratégias de ensino-aprendizagem para que o aluno portador de necessidades especiais dela se beneficie e nela permaneça.

Nessa perspectiva, Correia (2010) afirma que "as famílias devem ser consideradas membros valiosos da equipe e envolvidas nas tomadas de decisões. As práticas/políticas de atendimento às famílias devem ser amistosas, respeitadoras dos seus valores, estabelecendo prioridades e permitindo tempo para sua adaptação" (Correia, 2010, p. 35). Em razão disso, para os docentes, é fundamental que a escola mantenha uma relação próxima das famílias, em que o diálogo e o respeito sejam a base. O relacionamento da escola com as famílias deve primar por esclarecer dúvidas, apoiar e orientar nos momentos de insegurança e encorajar os pais a participarem ativamente tanto nos processos escolares como na busca pela garantia dos direitos de seus filhos, nos diferentes atendimentos e espaços em que estão inseridos (Correia, 2010).

\section{Posturas docentes necessárias à inclusão: atitudes profissionais ou benevolentes?}

O segundo conjunto de ações propostas pelos professores participantes da pesquisa está voltado às posturas docentes, consideradas por eles como necessárias, diante dos processos de inclusão na escola. De acordo com os participantes da pesquisa, os professores da sala de aula comum precisam desenvolver, além de saberes especializados sobre as deficiências e estratégias específicas de trabalho, atitudes e posturas favoráveis à inclusão na escola, entre as quais estão a necessidade de acreditarem na capacidade de aprendizagem dos estudantes incluídos, de terem disponibilidade para a formação em serviço e de estarem dispostos a uma educação escolar inclusiva.

Outras atitudes mencionadas pelos docentes referem-se à necessidade de "mudar as concepções sobre estudantes com deficiências", de 
desenvolver práticas de "mediação entre educadores e estudantes", de promover a "acessibilidade metodológica", de "flexibilizar o currículo", de compreender "especificidades dos alunos" e de "aceitar as diferenças". Além dessas atitudes, os professores de educação especial salientam que deve haver "real vontade para que a inclusão aconteça", "diálogo, paciência e afetividade" e "comprometimento e responsabilidade do professor em planejar pensando no aluno incluído", pois é necessário "romper com a ignorância".

Com relação aos professores, mais precisamente os de área, mostramse resistentes e, embora a inclusão escolar não seja um debate novo, ainda assim encontramos colegas usando o discurso da falta de conhecimento e de formação para trabalhar com a inclusão, e é difícil eu aceitar esta fala, em pleno século 21, com todas as oportunidades de acesso a informação e até de formação gratuita. (Professora N, 2016).

Na verdade, é muito mais fácil trabalhar com os professores até o $5^{\circ}$ ano, pois estes se mostram interessados e abertos a diálogos e mudanças. No ensino médio tudo fica mais complicado. Tem professores que aceitam a inclusão e querem fazer o melhor, outros "educadores" fingem que ela nem existe. (Professora O, 2016).

Percebe-se, ainda, pouca vontade dos professores regentes de classe, no acolhimento e trabalho com alunos diferentes. Estamos muito aquém da inclusão, no significado estrito e ideal da palavra. As salas de aulas tornaram-se depósitos de alunos diferentes... A matrícula de alunos especiais é aceita nas escolas por imposição legal, ficando evidente a pouca vontade dos educadores em trabalhar com alunos diferentes em sala de aula. (Professora P, 2016).

A premissa de que todos os sujeitos, independentemente de suas dificuldades e/ou potencialidades, podem aprender deve fundamentar o trabalho pedagógico nas escolas. Contudo, destaca-se que poucos professores (2/33) sinalizaram a necessidade de acreditar na possibilidade de aprendizagem dos estudantes com deficiência na escola inclusiva. Esses professores afirmam que:

É necessário acreditar que o aluno com deficiência pode avançar em seus conhecimentos. (Professora Q, 2016).

É preciso perceber que todos nós aprendemos alguma coisa, desde que a motivação e as possibilidades de aprendizagem sejam ressaltadas. (Professora R, 2016).

Os discursos que defendem a postura dos professores como profissionais que têm a missão de dar conta dos problemas da escola mediante um esforço individual/coletivo são amparados no entendimento da docência como uma "profissão de fé", embasada em práticas religiosas e de benevolência. Há a defesa de um professor que, "mesmo sem a estrutura necessária", precisa resolver os problemas da escola e, indiretamente, os problemas sociais de uma sociedade excludente. Garcia (2014) discute essa relação entre escola e sociedade e afirma que 
[...] uma lógica de análise linear da realidade social apoiada no princípio da educação como redentora das questões sociais tem contribuído para a difusão da ideia segundo a qual ao promover "educação inclusiva" a sociedade estará transformando-se em uma "sociedade inclusiva". (Garcia, 2014, p. 102).

Para atuar nessa nova escola, exige-se um novo professor que seja, na verdade, um "superprofessor" (Evangelista; Triches, 2014) diante do cenário proposto pela Política Nacional (Brasil. MEC, 2008). Um professor benevolente, flexível, reflexivo, dinâmico, criativo, gestor de recursos e tecnologias, afetivo, paciente, responsável e comprometido diante das múltiplas demandas em uma escola inclusiva (Evangelista; Triches, 2014). Nesse cenário, questiona-se: Afinal, qual o principal objetivo do trabalho dos professores na escola? Qual o seu objeto essencial de trabalho? Quais as reais atribuições dos professores na tarefa educativa escolar?

Nóvoa (2009), ao discutir sobre os objetivos das instituições escolares, destaca as múltiplas funções a elas atribuídas. Como uma "escola transbordante", ela é responsabilizada pela resolução de questões que fogem ao seu alcance. Nesse debate, o autor sinaliza a importância de outras entidades sociais se assumirem como coautoras nesses processos de atendimento a essas questões sociais para que a escola possa, efetivamente, trabalhar em nome de sua principal finalidade: a democratização do conhecimento. Para o autor, assumir a responsabilidade de lidar com diferentes questões sociais como se pudesse resolvê-las, em nome de um imperativo ético, "tem sido o erro maior da escola transbordante" (Nóvoa, 2009, p. 12).

A defesa de uma escola centrada na aprendizagem procura inverter a deriva transbordante de uma escola a quem a sociedade vai, progressivamente, atribuindo todas as missões. Não se trata de advogar o regresso a um qualquer passado mítico e, muito menos, de defender programas mínimos, o ensino do "ler, escrever e contar" ou as tendências do "back to basics". Estes movimentos, que ganharam grande importância face à crise da escola e à incapacidade de resposta perante a massificação do ensino, baseiam-se na defesa do ensino tradicional e têm-se revelado de uma enorme pobreza teórica e prática. Trata-se, bem pelo contrário, de abrir novas perspectivas que coloquem a aprendizagem, em toda a sua riqueza, no centro das nossas preocupações. (Nóvoa, 2009, p. 12).

A super-responsabilização da escola para desempenhar inúmeras missões atribui aos professores a responsabilidade de atender diferentes demandas para além do trabalho com o conhecimento. Os docentes são os sujeitos entendidos como "instrumentos" para a concretização dos projetos educacionais propostos. Nessa discussão, Nóvoa (1991, p. 12) aponta que, apesar das mudanças no campo profissional, em que se substituiu um conjunto de professores religiosos (sob o controle da Igreja) por professores laicos (sob o controle do Estado), "o modelo de professor continua muito próximo ao modelo do padre". Para o autor, a profissão do professor é 
[...] influenciada por crenças e atitudes morais e religiosas. A princípio, os professores aderem a uma ética e a um sistema normativo essencialmente religiosos; mas, mesmo quando a missão de educar é substituída pela prática de um ofício e a vocação cede o lugar à profissão, as motivações originais não desaparecem". (Nóvoa, 1991, p.13).

A escola inclusiva, mesmo sem toda a estrutura necessária, é uma escola, de acordo com os participantes dessa pesquisa, a ser construída por meio de ações coletivas para além das funções/atribuições docentes e que envolvem outros sujeitos coautores (escola, família, esferas governamentais). O discurso que salienta a necessidade de afetividade, diálogo, respeito e aceitação das diferenças, comprometimento e responsabilidade coloca o professor numa postura missionária, com a exigência de atitudes benevolentes consideradas essenciais para que o projeto da escola inclusiva seja possível. Além das suas atribuições profissionais, que abarcam o conhecimento de suas disciplinas e das estratégias metodológicas para o ensino e a aprendizagem, é preciso demonstrar afeto, ser paciente e ter real vontade para que a inclusão aconteça, mesmo sem toda a estrutura necessária.

\section{Considerações finais}

A pesquisa com professores de educação especial atuantes em diferentes contextos escolares tem o propósito de problematizar questões comuns que são características das distintas realidades. Sem a intenção de realizar comparações entre as diferentes realidades ou de metrificar em quais espaços os processos inclusivos estão mais ou menos desenvolvidos, esta investigação teve o objetivo de conhecer e refletir sobre as falas desses professores acerca de seus cotidianos de trabalho.

A crença nos processos inclusivos é defendida pelos docentes, que também apontam as dificuldades vivenciadas em suas práticas pedagógicas. Sinalizam muitas faltas de: apoio, formação, tempo, espaço, conhecimentos e inclusão. Contudo, indicam ações que, coerentes à Política Nacional (Brasil. MEC, 2008), parecem fundadas na esperança de uma nova escola.

As ações propostas são conferidas a um coletivo de pessoas envolvidas diretamente nos processos inclusivos: as famílias, as equipes pedagógicas e diretivas, os governos e todos os professores. Para eles, a inclusão não pode ser uma tarefa exclusiva, apesar dos discursos que os responsabilizam e das suas múltiplas atribuições definidas em resoluções: ${ }^{10}$ é uma tarefa para toda a sociedade.

Não obstante o sentimento de esperança que move esses professores por soluções para a efetivação de uma escola inclusiva, "mesmo sem toda a estrutura necessária", suspeitamos dos discursos que super-responsabilizam os docentes para tornar a escola um novo lugar e que consideram a escola como um remédio para as doenças sociais. Isso porque entendemos que

\footnotetext{
10 Cita-se a Resolução $\mathrm{n}^{\circ} \quad 4$, de 2 de outubro de 2009, que institui as Diretrizes Operacionais para o Atendimento Educacional Especializado na Educação Básica, modalidade educação especial.
} 
as atribuições da escola e do profissional se referem ao trabalho com o conhecimento e com a aprendizagem dos sujeitos, com deficiência ou não.

Contudo, será que a inclusão realmente pode se constituir em um processo para todos, sem distinção? Se há diferentes formas de aprender, por que todos têm de estar em um mesmo lugar, com os mesmos professores e com os mesmos processos de aprendizagem? Será que as ações propostas pelos professores de educação especial podem contribuir para transformar a realidade das escolas em que atuam? Se as políticas educacionais previrem efetivamente ações concretas, comprometidas com a democratização do conhecimento, talvez as ações propostas pelos professores se tornem estratégias para um novo lugar, em que o conhecimento seja um instrumento de luta pela democratização da sociedade e pela garantia de espaços de educação que sejam, verdadeiramente, inclusivos.

\section{Referências bibliográficas}

ANJOS, H. P.; ANDRADE, E. P.; PEREIRA, M. R. A inclusão escolar do ponto de vista dos professores: o processo de constituição de um discurso. Revista Brasileira de Educação, Rio de Janeiro, v. 14, n. 40, p. 116-129, jan./abr. 2009.

BARDIN, L. Análise de conteúdo. Lisboa: Ed. 70, 1977.

BELLO, I. M.; BUENO, B. O. Programas especiais de formação superior de professores no Brasil: a universitarização do magistério em questão. Arquivos Analíticos de Políticas Educativas, v. 20, n. 6, p. 1-19, fev. 2012.

BRASIL. Lei no 9.394, de 20 de dezembro de 1996. Estabelece as diretrizes e bases da educação nacional. Diário Oficial da União, Brasília, 23 dez. 1996. Seção 1, p. 27833.

BRASIL. Decreto n ${ }^{\circ} 6.571$, de 17 de setembro de 2008. Dispõe sobre o atendimento educacional especializado, regulamenta o parágrafo único do artigo 60 da lei n. 9.394, de 20 de dezembro de 1996, e acrescenta dispositivo ao decreto n. 6.253, de 13 de novembro de 2007. Diário Oficial da União, Brasília, 18 set. 2008. Seção 1, p. 26.

BRASIL. Lei no 13.005 de 25 de junho de 2014. Aprova o Plano Nacional de Educação - PNE e dá outras providências. Diário Oficial da União, Brasília, 26 jun. 2014. Seção 1, p. 1.

BRASIL. Conselho Nacional de Educação (CNE). Câmara da Educação Básica (CEB). Resolução CNE/CEB n 2, de 11 de setembro de 2001. Institui diretrizes nacionais para a educação especial na educação básica. Diário Oficial da União, Brasília, 14 set. 2001. Seção 1, p. 39. 
BRASIL. Conselho Nacional de Educação (CNE). Câmara da Educação Básica (CEB). Resolução no 4, de 2 de outubro de 2009. Institui diretrizes operacionais para o atendimento educacional especializado na educação básica, modalidade educação especial. Diário Oficial da União, Brasília, 5 out. 2009. Seção 1, p. 17.

\section{BRASIL. Ministério da Educação (MEC). Política Nacional} de Educação Especial na perspectiva da educação inclusiva. Brasília, 2008. Disponível em: <http://portal.mec.gov.br/ arquivos/pdf/ politicaeducespecial.pdf $>$ Acesso em: 20 maio 2017.

CORREIA, L. M. (Org.). Educação especial e inclusão: quem disser que uma sobrevive sem a outra não está no seu perfeito juízo. 2. ed. Porto: Porto Editora, 2010.

COSTAS, F. A. T.; HONNEF, C. O trabalho docente articulado como proposta pedagógica para educação especial na perspectiva inclusiva no ensino médio e tecnológico. Arquivos Analíticos de Políticas Educativas, v. 23, n. 35, p. 1-16, mar. 2015.

EVANGELISTA, O.; TRICHES, J. Professor: a profissão que pode mudar um país? In: EVANGELISTA, O. (Org.). O que revelam os slogans na política educacional. Araraquara: Junqueira \& Marin, 2014. p. 47-82.

GARCIA, R. M. C. Política de educação especial na perspectiva inclusiva e a formação docente no Brasil. Revista Brasileira de Educação, Rio de Janeiro, v. 18, n. 52, p. 101-119, jan./mar. 2013.

GARCIA, R. M. C. Para além da 'inclusão': crítica às políticas educacionais contemporâneas. In: EVANGELISTA, O. (Org.). O que revelam os slogans na política educacional. Araraquara: Junqueira \& Marin, 2014. p. 101-140.

KASSAR, M. C. M. A formação de professores para a educação inclusiva e os possíveis impactos na escolarização de alunos com deficiências. Cadernos Cedes, Campinas, v. 34, n. 93, p. 207-224, maio/ago. 2014.

LOPES, R. P. V.; MARQUEZAN, R. O envolvimento da família no processo de integração/inclusão do aluno com necessidades especiais. Revista Educação Especial, Santa Maria, n. 15, p. 1-4, 2010.

MARCONI, M. A.; LAKATOS, E. M. Fundamentos de metodologia científica. 6. ed. São Paulo: Atlas, 2009.

MICHELS, M. H. O que há de novo na formação de professores para a Educação Especial? Revista Educação Especial, Santa Maria, v. 24, n. 40, p. 219-232, maio/ago. 2011. 
MENDES, E. G.; ALMEIDA, M. A.; TOYODA, C. Y. Inclusão escolar pela via da colaboração entre educação especial e educação regular. Educar em Revista, Uberlândia, n. 41, p. 80-93, 2011.

NÓVOA, A. O passado e o presente dos professores. In: NÓVOA, A. (Org.). Profissão professor. Porto: Porto Editora, 1991.

NÓVOA, A. Educação 2021: para uma história do futuro. Revista Iberoamericana de Educación, n. 49, p.1-18, jan./abr. 2009.

RODRIGUES, M. M. Matrizes e repercussões da educação ao longo da vida como política educacional. In: EVANGELISTA, O. (Org.). O que revelam os slogans na política educacional. Araraquara: Junqueira \& Marin, 2014. p. 203-243.

SCHMIDT, C. et al. Inclusão escolar e autismo: uma análise da percepção docente e práticas pedagógicas. Psicologia: teoria e prática, v. 18, n. 1, p. 222-235, jan./abr. 2016.

SHIROMA, E.; EVANGELISTA, O. Apresentação. In: EVANGELISTA, O. (Org.). O que revelam os slogans na política educacional. Araraquara: Junqueira \& Marin, 2014. p. 11-20.

ORGANIZAÇÃO DAS NAÇÕES UNIDAS PARA A EDUCAÇÃO, A CIÊNCIA E A CULTURA (Unesco). Declaração Mundial sobre a Educação para Todos: satisfação das necessidades básicas de aprendizagem: Jomtien, 1990. [S.1.]: Unesco, 1998.

VILARONGA, C. A. R.; MENDES, E. G. Ensino colaborativo para o apoio à inclusão escolar: práticas colaborativas entre os professores. Revista Brasileira de Estudos Pedagógicos, Brasília, v. 95, n. 239, p. 139-151, jan./ abr. 2014.

Recebido em 4 de setembro de 2017.

Solicitação de correções em 14 de fevereiro de 2018.

Aprovado em 22 de março de 2018. 